\title{
Pyrrocidine A, a metabolite of endophytic fungi, has a potent apoptosis-inducing activity against HL60 cells through caspase activation via the Michael addition
}

\author{
Shota Uesugi ${ }^{1}$, Nozomi Fujisawa ${ }^{2}$, Jun Yoshida ${ }^{3}$, Mitsuru Watanabe ${ }^{4}$, Shingo Dan ${ }^{5}$, Takao Yamori ${ }^{5,6}$, \\ Yoshihito Shiono ${ }^{7}$ and Ken-ichi Kimura ${ }^{1,2}$
}

Pyrrocidine $A$ is a known antimicrobial compound produced by endophytic fungi and has a unique 13-membered macrocyclic alkaloid structure with an $\boldsymbol{\alpha}, \boldsymbol{\beta}$-unsaturated carbonyl group. We have previously reported that pyrrocidine $A$ shows potent cytotoxicity against human acute promyelocytic leukemia HL60 cells, and the activity is 70-fold higher than that of pyrrocidine $B$ which is the analog lacking the $\boldsymbol{\alpha}, \boldsymbol{\beta}$-unsaturated carbonyl group. Pyrrocidine A induced nuclear condensation, DNA fragmentation and caspase activation in HL60 cells. Since the DNA fragmentation was suppressed by pretreatment with the pancaspase inhibitor, benzyloxycarbonyl-Val-Ala-Asp (OMe) fluoromethylketone (z-VAD-fmk), caspase-mediated apoptosis contributes to pyrrocidine A-induced cytotoxicity. JFCR39 human cancer cells panel indicated that the mechanism of action of pyrrocidine A is different from other clinical anticancer drugs, and this compound broadly inhibited the growth of various cancer cell lines. The apoptosis induction by pyrrocidine $\mathrm{A}$ was suppressed by both $\mathrm{N}$-acetyl-L-cysteine (NAC) and glutathione, both of which are thiolcontaining antioxidants. Furthermore, pyrrocidine A directly bound to $\mathrm{N}$-acetyl-L-cysteine methyl ester (NACM) through the Michael-type addition at the $\boldsymbol{\alpha}, \boldsymbol{\beta}$-unsaturated carbonyl group and was detected by HPLC and liquid chromatography-ESI-tandem MS (LC-ESI-MS/MS) analyses. This indicates that this moiety is crucial for the potent apoptosis-inducing activity of pyrrocidine A.

The Journal of Antibiotics (2016) 69, 133-140; doi:10.1038/ja.2015.103; published online 28 October 2015

\section{INTRODUCTION}

Microbial metabolites contain bioactive compounds that have a huge variety of chemical structures or biological activities. ${ }^{1}$ These compounds have characteristics such as rich chiral centers and heterocyclic structures containing oxygen atoms, and these features are involved in the interaction with proteins and DNA. They are therefore considered as promising lead compounds for the development of clinical drugs. $^{2}$ Endophytic fungi are microorganisms living together with host plants, and much of the mode of life and production of metabolites remains to be clarified. ${ }^{3,4}$ Recently, many novel bioactive compounds have been isolated from endophytic fungi, ${ }^{5,6}$ and they are expected to be a novel source of clinical drugs or bioprobes. We have found the novel bioactive compounds, anthracobic acids $\mathrm{A}$ and $\mathrm{B},{ }^{7}$ eremoxylarins $\mathrm{A}$ and $\mathrm{B}$ (inhibitors of calcineurin), ${ }^{8,9}$ benzophomopsin $\mathrm{A},{ }^{10}$ allantopyrone $\mathrm{A}$ (an inhibitor of NF-kB signaling) 11,12 $^{13}$ bispyrrocidine (an inhibitor of prolyl oligopeptidase $)^{13}$ as metabolites of endophytic fungi.

Pyrrocidines A and B (Figure 1) were first isolated from the fungus Cylindrocarpon sp. LL-Cyan 426 by $\mathrm{He}$ et al., ${ }^{14}$ and were also isolated from an endophytic fungus Acremonium zeae by Wicklow and Poling. ${ }^{15}$ These compounds have characteristic structures, which include a cis,trans-fused tricyclic decahydrofluorene core and a 13 -membered macrocycle containing a $\gamma$-hydroxy- $\gamma$-lactam ring. In addition, only pyrrocidine $\mathrm{A}$ contained an $\alpha, \beta$-unsaturated carbonyl group, and showed potent antimicrobial activity toward Gram-positive bacteria including drug-resistant strains, whereas pyrrocidine B was much less active. ${ }^{15}$ Based on these interesting chemical and biological properties, the total synthesis of pyrrocidine $\mathrm{A}$ has been carried out. ${ }^{16}$ We have isolated pyrrocidines A, B and its derivatives from the plant-associated fungus Neonectria ramulariae Wollenw KS-246. ${ }^{17}$ Furthermore, we have found that pyrrocidine A showed the most potent cytotoxicity against human promyelocytic leukemia HL60 cells with an $\mathrm{IC}_{50}$ value of $0.12 \mu \mathrm{M}$. However, the mechanism of pyrrocidine A-induced cancer cell growth inhibition still remains unclear.

In this study, we investigated the mechanism of growth inhibition induced by pyrrocidine A against human acute promyelocytic leukemia HL60 cells.

\footnotetext{
${ }^{1}$ The United Graduate School of Agricultural Sciences, Iwate University, Iwate, Japan; ${ }^{2}$ Graduate School of Agriculture, Iwate University, Iwate, Japan; ${ }^{3}$ Center for Liberal Arts and Sciences, Iwate Medical University, Iwate, Japan; ${ }^{4}$ National Agricultural Research Center for Tohoku Region (NARCT), Iwate, Japan; ${ }^{5}$ Division of Molecular Pharmacology, Cancer Chemotherapy Center, Japanese Foundation for Cancer Research, Tokyo, Japan; ${ }^{6}$ Center for Product Evaluation, Pharmaceuticals and Medical Device Agency, Tokyo, Japan and ${ }^{7}$ Faculty of Agriculture, Yamagata University, Yamagata, Japan

Correspondence: Dr K Kimura, The United Graduate School of Agricultural Sciences, Iwate University, 3-18-8 Ueda, Morioka, Iwate 020-8550, Japan.

E-mail: kimurak@iwate-u.ac.jp

Received 7 June 2015; revised 22 July 2015; accepted 18 August 2015; published online 28 October 2015
} 


\section{MATERIALS AND METHODS}

\section{Isolation of pyrrocidines $A$ and $B$}

Pyrrocidines A and B were obtained from N. ramulariae Wollenw KS-246 that was isolated from a dead branch collected from Mt. Gassan in Yamagata, Japan. The isolation procedure was described in a previous report. ${ }^{17}$

\section{Cell line and culture}

HL60 cells (RCB0041, RIKEN BioResource Center, Tsukuba, Japan) were grown in RPMI-1640 medium (Gibco, Invitrogen, Carlsbad, CA, USA) supplemented with $10 \%$ heat-inactivated fetal bovine serum (BioWest, Vancouver, BC, Canada) and penicillin (50 units per $\mathrm{ml}$ )-streptomycin

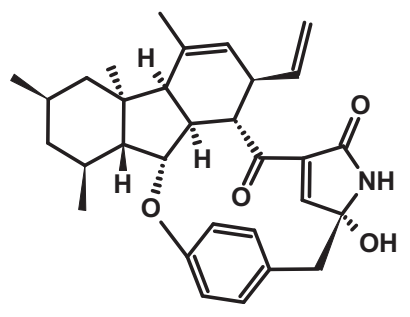

Pyrrocidine A (1)

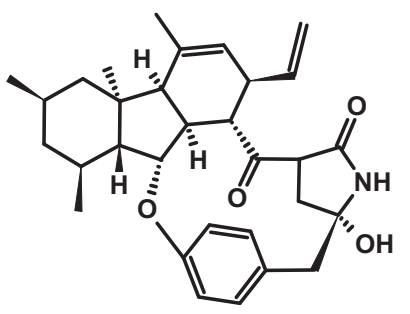

Pyrrocidine B (2)
Figure 1 Chemical structures of pyrrocidine A (1) and pyrrocidine B (2). $\left(50 \mu \mathrm{g} \mathrm{ml}^{-1}\right)$ (Gibco, Invitrogen) in a humidified atmosphere at $37^{\circ} \mathrm{C}$ under $5 \% \mathrm{CO}_{2}$.

\section{DNA gel electrophoresis}

HL60 cells $\left(5 \times 10^{5}\right.$ cells per well) were treated with pyrrocidine A in a 24 -well plate and were washed with phosphate-buffered saline (PBS). Cell pellets were resuspended in lysis buffer (100 mM Tris- $\mathrm{HCl}$ (pH 8.0), 25 mM EDTA, 0.2\% SDS and $0.1 \%$ RNase $\mathrm{A}$ ), and incubated for $1 \mathrm{~h}$ at $50^{\circ} \mathrm{C}$. The lysates were then incubated for an additional $1 \mathrm{~h}$ at $50^{\circ} \mathrm{C}$ with $1 \mathrm{mg} \mathrm{ml}^{-1}$ of proteinase $\mathrm{K}$ (Wako Pure Chemical Industries, Osaka, Japan) and then protein was precipitated with $1.5 \mathrm{M} \mathrm{NaCl}$. After centrifugation $\left(15000 \mathrm{~g}\right.$ for $20 \mathrm{~min}$ at $4^{\circ} \mathrm{C}$ ), the supernatant was collected and DNA was precipitated with cold ethanol. DNA samples were then subjected to electrophoresis on a $2 \%$ agarose gel (Dojindo Laboratories, Kumamoto, Japan) in TBE (Tris-Borate-EDTA) buffer (Takara Bio, Shiga, Japan) for $90 \mathrm{~min}$ at $50 \mathrm{~V}$. After the electrophoresis, the gel was stained with $10 \mu \mathrm{g} \mathrm{ml} \mathrm{g}^{-1}$ of ethidium bromide and photographed. Benzyloxycarbonyl-Val-Ala-Asp (OMe) fluoromethylketone (z-VAD-fmk) (Enzo Life Sciences, New York, NY, USA), glutathione (GSH (reduced form)), ascorbic acid (Wako Pure Chemical Industries), $\mathrm{N}$-acetyl-L-cysteine (NAC), $\mathrm{N}$-acetyl-L-cysteine methyl ester (NACM) and $\alpha$-tocopherol (Sigma-Aldrich, St Louis, MO, USA) were added to the cell culture at $1 \mathrm{~h}$ before exposure to pyrrocidine $\mathrm{A}$.

\section{Microscopic observation}

HL60 cells $\left(5 \times 10^{5}\right.$ cells per well $)$ were treated with pyrrocidine A for $2 \mathrm{~h}$ in a 24-well plate. Cells were washed with PBS and stained with $20 \mu \mathrm{M}$ Hoechst
A
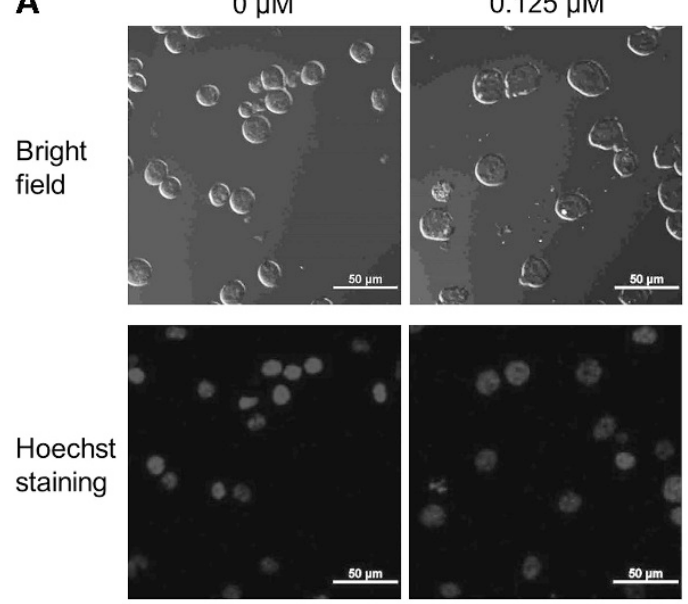

B
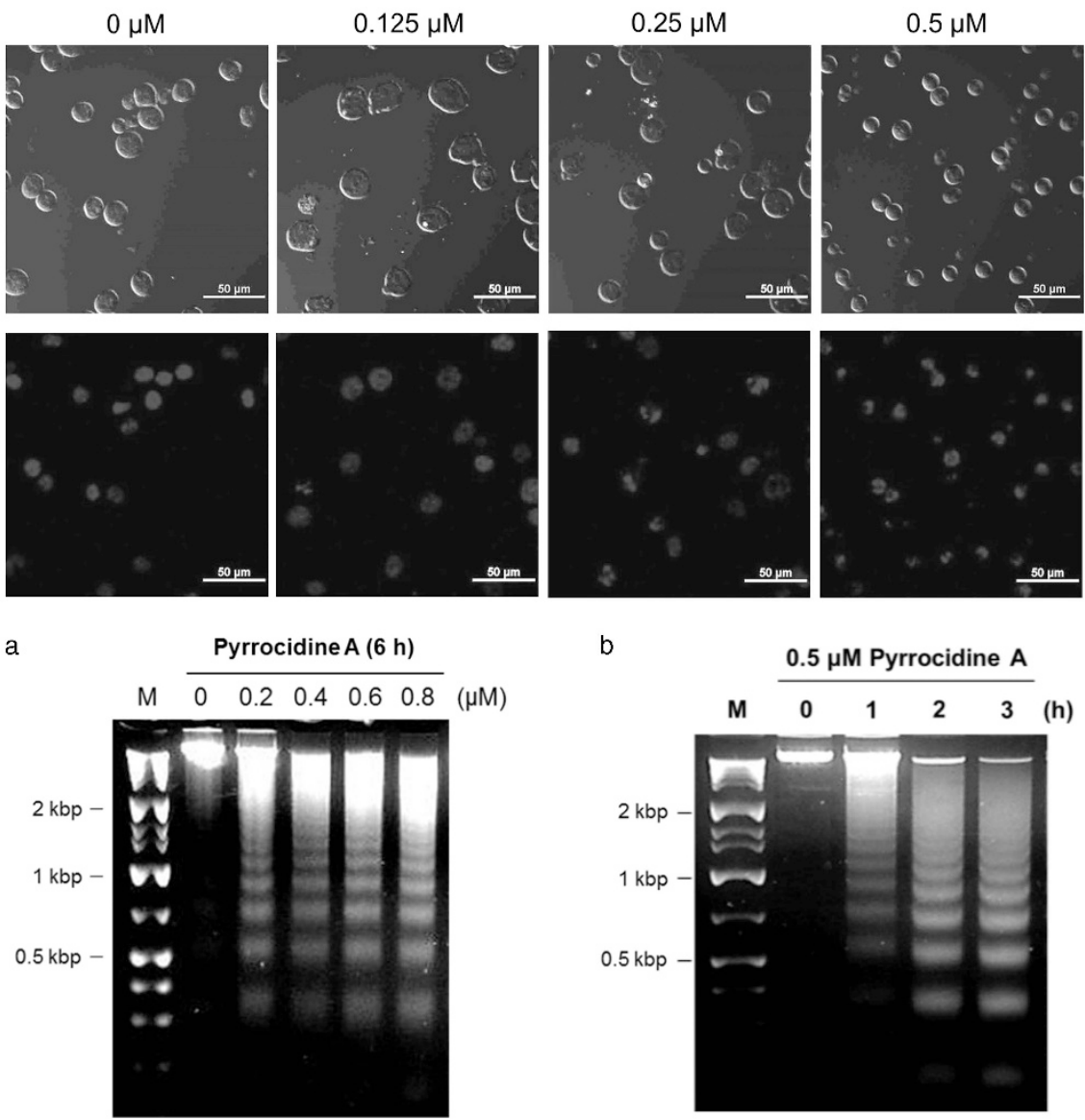

b

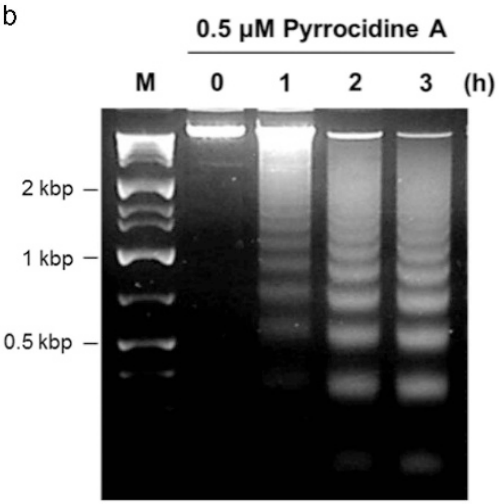

Figure 2 Pyrrocidine A induces apoptotic morphological changes and DNA fragmentation in HL60 cells. (A) Microscopic observation of morphological changes. HL60 cells were treated with pyrrocidine A for $2 \mathrm{~h}$, and then stained with Hoechst 33342 . Stained cells were observed using a confocal laser microscope. (B) DNA fragmentation. HL60 cells were treated with pyrrocidine A at indicated concentrations for $6 \mathrm{~h}$ (a) or $0.5 \mu \mathrm{m}$ for indicated times (b). DNA was separated with $2 \%$ agarose gel electrophoresis, and the gel was stained with ethidium bromide. A full color version of this figure is available at The Journal of Antibiotics journal online. 
33342 (Dojindo Laboratories) for $15 \mathrm{~min}$ at $37^{\circ} \mathrm{C}$. Stained cells were washed with PBS and suspended with $20 \mu \mathrm{l}$ of fresh RPMI-1640 medium. Finally, cells were examined using a confocal laser microscope (C2, Nikon, Tokyo, Japan).

\section{Protein extraction}

HL60 cells $\left(5 \times 10^{6}\right.$ cells per dish) were treated with pyrrocidine A for $3 \mathrm{~h}$ in a $100-\mathrm{mm}$ dish, and the cells were washed with PBS. Total protein was extracted using RIPA buffer (10 mm Tris- $\mathrm{HCl}$ (pH 7.5), 1\% NP-40, $0.01 \%$ sodium deoxycholate, $0.1 \%$ SDS, $150 \mathrm{~mm} \mathrm{NaCl}$ and $1 \mathrm{~mm}$ EDTA) containing protease inhibitor cocktail Complete Mini (Roche Diagnostics, Basel, Switzerland) and phosphatase inhibitor cocktail (Wako Pure Chemical Industries) by incubating at $4{ }^{\circ} \mathrm{C}$ for $30 \mathrm{~min}$. After centrifugation $\left(15000 \mathrm{~g}\right.$ for $30 \mathrm{~min}$ at $\left.4{ }^{\circ} \mathrm{C}\right)$, supernatant was collected as cell lysate and the protein concentrations were determined using a BCA protein assay kit (Pierce, Waltham, MA, USA). The cytosolic protein was extracted using CLAMI (cell lysis and mitochondria intact) buffer (250 mM sucrose, $70 \mathrm{~mm} \mathrm{KCl}$ in PBS) containing $10 \mathrm{mg} \mathrm{ml}^{-1}$ digitonin, protease inhibitor cocktail and phosphatase inhibitor cocktail by incubating on ice for $5 \mathrm{~min}$. The cell suspension was centrifuged at 1200 r.p.m. at $4{ }^{\circ} \mathrm{C}$. The supernatant was collected as the cytosolic fraction. The protein concentrations were determined by the BCA method.

\section{Western blotting}

The prepared samples containing $20 \mu \mathrm{g}$ total protein were loaded onto SDSpolyacrylamide gels. After electrophoresis, proteins were transferred onto a PVDF membrane (Millipore, Billerica, MA, USA) and blocking was performed in TBS (Tris-buffered saline) containing $1 \%$ polyvinylpyrrolidone and $0.1 \%$ Tween-20. The membranes were then incubated with primary antibodies. After washing membranes with $0.1 \%$ Tween-20 in TBS (TBS-T), each blot was incubated with horseradish peroxidase-conjugated secondary antibodies. The protein bands were detected using ECL ${ }^{\mathrm{TM}}$ (GE Healthcare, Little Chalfont, England) and ImageQuant LAS 4000 (GE Healthcare, Piscataway, NJ, USA). Primary antibodies against caspase-3, caspase-9, PARP, Bid and cytochrome $c$ were purchased from Cell Signaling Technology, Danvers, MA USA, those against caspase-8, Bax, and Bcl-2 were purchased from Becton Dickinson Biosciences, Franklin Lakes, NJ, USA, and the antibody against $\alpha$-tubulin was purchased from Santa Cruz Biotechnology, Santa Cruz, CA, USA. Secondary antibodies, horseradish peroxidase-conjugated anti-mouse IgG and anti-rabbit IgG were purchased from Cell Signaling Technology.

\section{COMPARE analysis}

A panel of 39 human cancer cell lines, known as JFCR39, was used as described previously. ${ }^{18}$ All the cell lines were cultured in RPMI-1640 medium

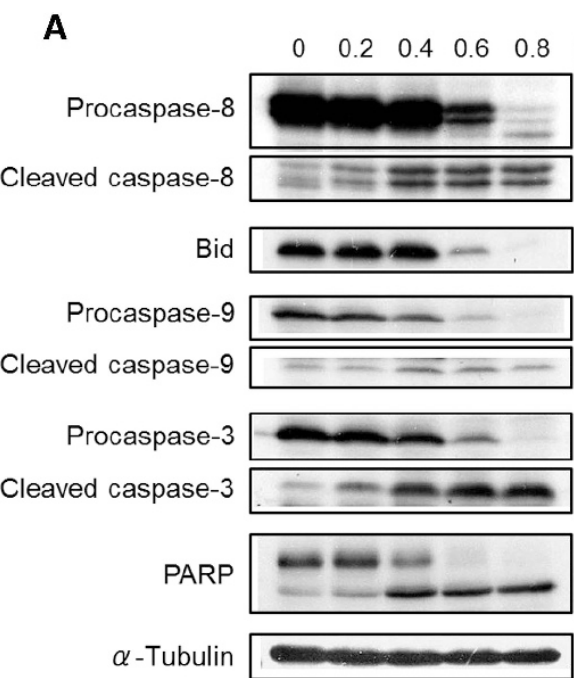

C

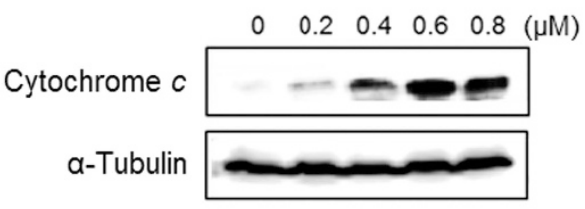

B
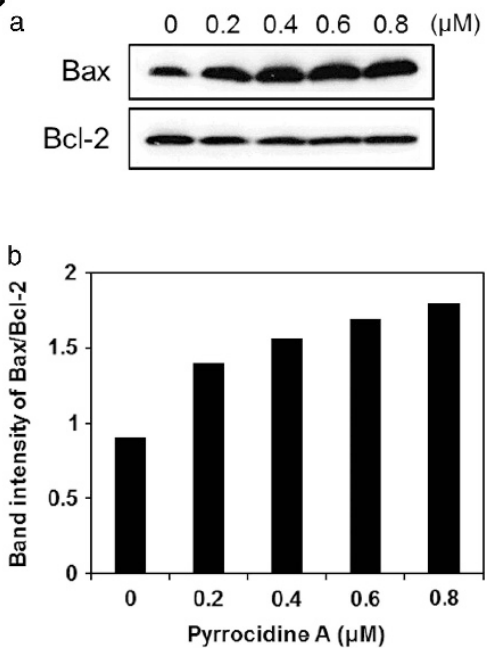

D

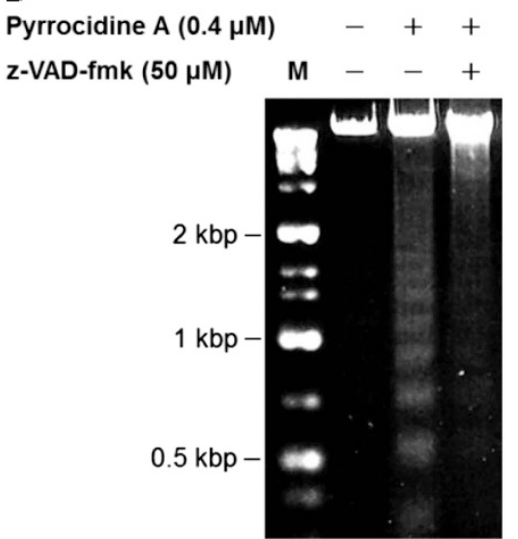

Figure 3 Effect of pyrrocidine A on apoptosis pathway. (A) Pyrrocidine A cleaved caspases and its substrates (Bid and PARP). HL60 cells were treated with pyrrocidine $A$ at indicated concentrations for $6 \mathrm{~h}$, and the cell lysate was subjected to western blotting. (B) The protein expression levels of Bax and Bcl-2. (a) HL60 cells were treated with pyrrocidine A for $6 \mathrm{~h}$, the expression levels of Bax and Bcl-2 were determined by western blot analysis. (b) Ratio of the protein levels of Bax/Bcl-2. (C) Release of cytochrome $c$ to cytosolic fraction. HL60 cells were treated with pyrrocidine A at indicated concentrations for $6 \mathrm{~h}$, and cytosolic fraction of cell lysate was subjected to western blotting. (D) Effect of pan-caspase inhibitor on DNA fragmentation. HL60 cells were preincubated with $50 \mu \mathrm{m} z-V A D$-fmk for $1 \mathrm{~h}$ before treatment with $0.4 \mu \mathrm{m}$ pyrrocidine $\mathrm{A}$ for $6 \mathrm{~h}$. 
supplemented with $5 \%$ fetal bovine serum, penicillin $\left(100 \mathrm{U} \mathrm{ml}^{-1}\right)$ and streptomycin $\left(100 \mu \mathrm{g} \mathrm{ml}^{-1}\right)$ at $37^{\circ} \mathrm{C}$ in humidified air containing $5 \% \mathrm{CO}_{2}$.

\section{Detection of intracellular reactive oxygen species level}

Intracellular reactive oxygen species (ROS) level was detected using $2^{\prime}, 7^{\prime}$ dichlorofluorescin diacetate (DCFH-DA). HL60 cells $\left(5 \times 10^{4}\right.$ cells per well) were treated with pyrrocidine A for $1 \mathrm{~h}$ in a 96-well white plate. After treatment, $10 \mu \mathrm{M}$ DCFH-DA (Sigma-Aldrich) was added to wells $30 \mathrm{~min}$ before measurement. Fluorescent intensity (excitation/emission wavelength $=530 / 590$ $\mathrm{nm}$ ) was measured using a micro plate reader (Infinite F200 PRO, Tecan, Männedorf, Switzerland).

\section{Reaction of pyrrocidine A with NACM}

Pyrrocidines A and B ( $1 \mathrm{~mm}$ ) were incubated with $10 \mathrm{~mm}$ NACM in $40 \mu \mathrm{l}$ of $70 \% \mathrm{MeOH}$ solution for $1 \mathrm{~h}$ at $37^{\circ} \mathrm{C}$. The reaction was monitored by analytical HPLC [column: Capcell pak $\mathrm{C}_{18}, 4.6 \mathrm{~mm}$ i.d. $\times 150 \mathrm{~mm}$ (Shiseido, Tokyo, Japan); mobile phase: $\mathrm{MeOH}:$ water $=80: 20(\mathrm{v} / \mathrm{v})$; flow rate: $1.0 \mathrm{ml}$ per minute, $5 \mu \mathrm{l}$ injection] equipped with an 880-PU pump and a MD-910 multi-channel detector (Japan spectroscopic (Jasco), Tokyo, Japan).

\section{Structure elucidation of a conjugate by MS}

Structure elucidation of a pyrrocidine A-NACM conjugate was performed by liquid chromatography-ESI-tandem MS (LC-ESI-MS/MS) spectrum. Pyrrocidine A (20 mM) was incubated with or without $40 \mathrm{~mm}$ NACM in $100 \mu \mathrm{l}$ of $70 \%$ $\mathrm{MeOH}$ for $30 \mathrm{~min}$ at $37^{\circ} \mathrm{C}$. The reaction sample was introduced to ESI-MS/MS apparatus (QSTAR Pulsar i, Applied Biosystems, the present AB SCIEX, Framingham, MA, USA) by HPLC as described above using a flow rate of $0.2 \mathrm{ml}$ per minute and $1 \mu \mathrm{l}$ injection.

\section{RESULTS}

Pyrrocidine A induces apoptosis in HL60 cells

Pyrrocidine A potently inhibits the growth of HL60 cells with an $\mathrm{IC}_{50}$ value of $0.12 \mu \mathrm{M}$. To characterize the mechanism of growth inhibition induced by pyrrocidine $\mathrm{A}$, we examined the nuclear morphological changes. HL60 cells treated with pyrrocidine A were stained with Hoechst 33342 and observed by confocal laser microscope. The nuclear condensation, a principal characteristic of apoptosis, was detected in a dose-dependent manner (Figure 2A). In addition, pyrrocidine A induced DNA fragmentation in a dose- and timedependent manner (Figure 2B). These results indicated that pyrrocidine A induces apoptosis against HL60 cells.

Effects of pyrrocidine A on apoptosis-related proteins

In apoptosis, the activation of caspases has important roles, and treatment of pyrrocidine A induced cleavage of caspases-3, 8 and 9 in a dose-dependent manner (Figure 3A). In addition, Bid and PARP, substrates of caspase- 8 and caspase- 3 , respectively, were also cleaved at the same concentration with each caspase activation (Figure $3 \mathrm{~A}$ ). These changes clearly indicate that pyrrocidine A activates caspase pathways in HL60 cells. Furthermore, the protein level of proapoptotic Bax was upregulated by pyrrocidine $\mathrm{A}$, whereas antiapoptotic Bcl-2 was not affected (Figure 3B (a)). The ratio of Bax/ $\mathrm{Bcl}-2$ was increased in a dose-dependent manner (Figure 3B (b)) and this is considered as an important event in activation of mitochondriameditated apoptosis pathways through induction of the mitochondrial outer membrane permeabilization (MOMP). ${ }^{19}$ Indeed, we confirmed that cytochrome $c$, a mitochondria-localized protein, was released to the cytosol in a dose-dependent manner (Figure 3C). Furthermore, a pan-caspase inhibitor, z-VAD-fmk, suppressed the DNA fragmentation induced by pyrrocidine A (Figure 3D). These results indicated that pyrrocidine $\mathrm{A}$ induces apoptosis through caspase activation in HL60 cells.

\section{COMPARE analysis by JFCR39 cancer panel}

To characterize the mode of action of pyrrocidine A, we subjected this compound to a panel of 39 human cancer cell lines (JFCR39). ${ }^{18}$ In this system, the mode of action of bioactive compounds can be revealed by comparing the similarity of sensitivity against each cancer cell line with well-known drugs. As a result, it was indicated that a pattern of sensitivity against various cancer cells of pyrrocidine A was different from other clinical drugs (correlation coefficient COMPARE Analysis $r<0.337$ ) (Figure 4). In addition, pyrrocidine A exhibits potent cytotoxicity against all of the 39 cell lines [MG-MID (mean of $\log \mathrm{GI}_{50}$ values for all 39 cell lines)=-6.64; Delta (difference between the MG-MID and the Log $\mathrm{GI}_{50}$ value for the most sensitive cell line) $=0.14$; Range (difference between the Log $\mathrm{GI}_{50}$ values for the most resistant cell line and the most sensitive cell line) $=0.56]$.

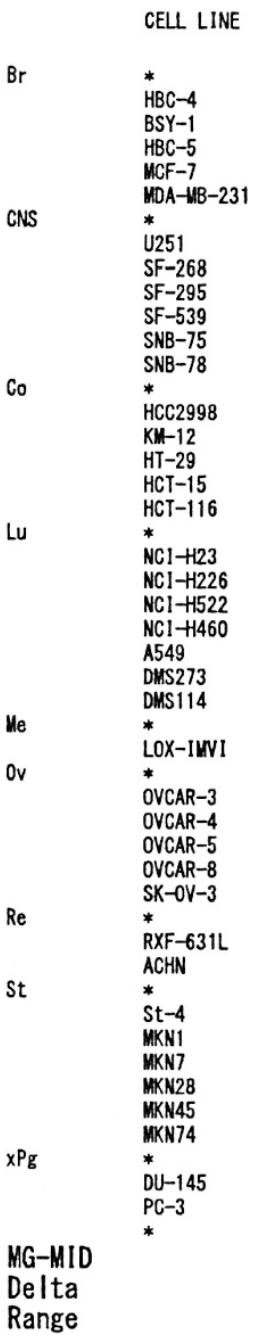

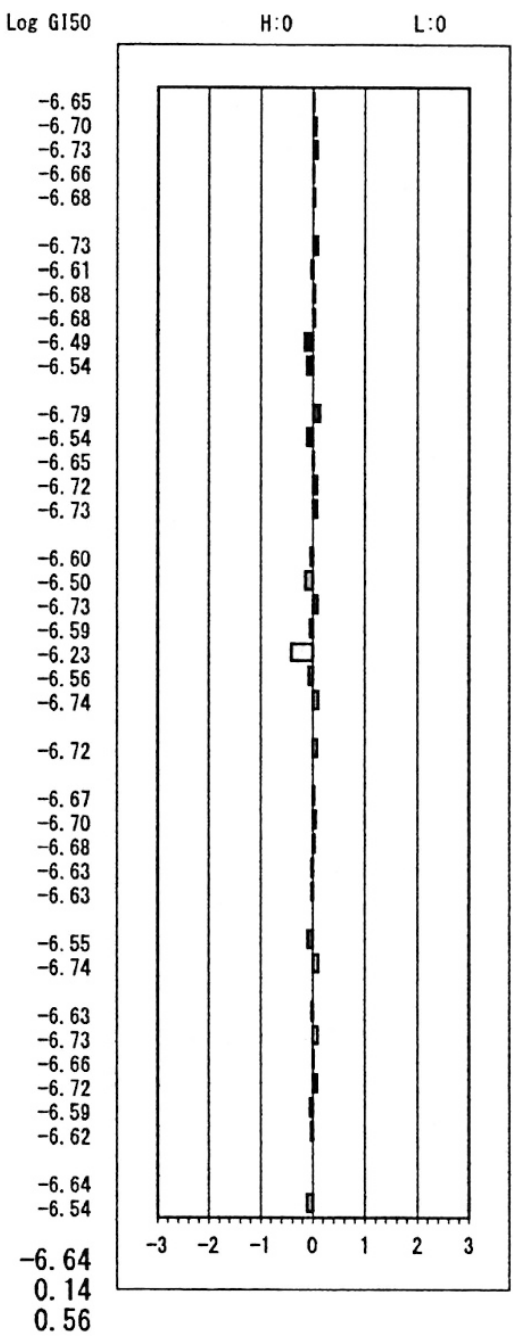

Figure 4 JFCR39 fingerprint of pyrrocidine $A$. The $X$ axis shows the difference in logarithmic scale between the mean of $\log \mathrm{GI}_{50}$ value for all 39 cell lines (MG-MID, expressed as 0 in the fingerprint) and the Log $\mathrm{GI}_{50}$ for each cell line in the JFCR39 panel. Columns to the right of 0 indicate the sensitivity of the cell lines to a pyrrocidine $A$ and columns to the left indicated the resistance. MG-MID = mean of $\mathrm{Log} \mathrm{GI}_{50}$ values for all 39 cell lines; delta=difference between the MG-MID and Log $\mathrm{GI}_{50}$ value for the most sensitive cell line; range $=$ reference between the $\log \mathrm{GI}_{50}$ value for the most resistant cell line and the most sensitive cell line. 
NAC and glutathione suppress pyrrocidine A-induced apoptosis Pyrrocidine A has an $\alpha, \beta$-unsaturated carbonyl moiety as a characteristic chemical structural unit. This moiety is well known as being highly reactive with nucleophiles such as thiol group and is one of the pharmacophores that contribute to various biological activities of small molecules. Pretreatment with NAC or GSH, containing a nucleophilic thiol group, significantly suppressed DNA fragmentation induced by pyrrocidine A in HL60 cells (Figure 5a). On the other hand, other antioxidants, ascorbic acid and $\alpha$-tocopherol, which do not have a thiol group, did not suppress the DNA fragmentation induced by pyrrocidine A. Furthermore, cleavage of caspases, increase of Bax/Bcl-2 ratio and release of cytochrome $c$ induced by pyrrocidine $\mathrm{A}$ were also clearly suppressed by NAC or GSH (Figures 5b-d). In addition, intracellular ROS level was only increased at more than $2.5 \mu \mathrm{M}$ of pyrrocidine A after $1 \mathrm{~h}$ using DCFH-DA (Figure 5e) even though DNA fragmentation was clearly formed by pyrrocidine A treatment at $0.5 \mu \mathrm{M}$ for $1 \mathrm{~h}$ (Figure 2B). These results indicated that NAC and GSH can inhibit pyrrocidine A-induced apoptosis through an ROS-independent manner.
Pyrrocidine A directly binds to NACM through the Michael addition

Many electrophilic compounds bind covalently with their target proteins through the Michael-type addition. To confirm the reactivity of $\alpha, \beta$-unsaturated carbonyl group with the nucleophilic functional group of NACM, we investigated the direct reactivity of pyrrocidine A with NACM using HPLC and LC-ESI-MS/MS systems. Pyrrocidine A can bind to NACM immediately and a new peak (a pyrrocidine A-NACM conjugate) was observed during the $1 \mathrm{~h}$ reaction. However, pyrrocidine B cannot bind to NACM and a peak of pyrrocidine B was not changed for the 1-h reaction (Figure 6A). A new peak (a pyrrocidine A-NACM conjugate) was analyzed using LC-ESI-MS/ MS and a dehydration ion peak of pyrrocidine A-NACM conjugate via the Michael addition $(\mathrm{m} / \mathrm{z}=647)$ and its fragment ion (cleavage of $\mathrm{C}_{13}-\mathrm{O}$ and $\left.\mathrm{C}_{19}-\mathrm{C}_{20}\right)(\mathrm{m} / \mathrm{z}=541)$ were observed (Figure $\left.6 \mathrm{~B}\right) .{ }^{20}$

\section{DISCUSSION}

Pyrrocidine A isolated from endophytic fungi is known as a potent antimicrobial compound, and we have found that pyrrocidine A

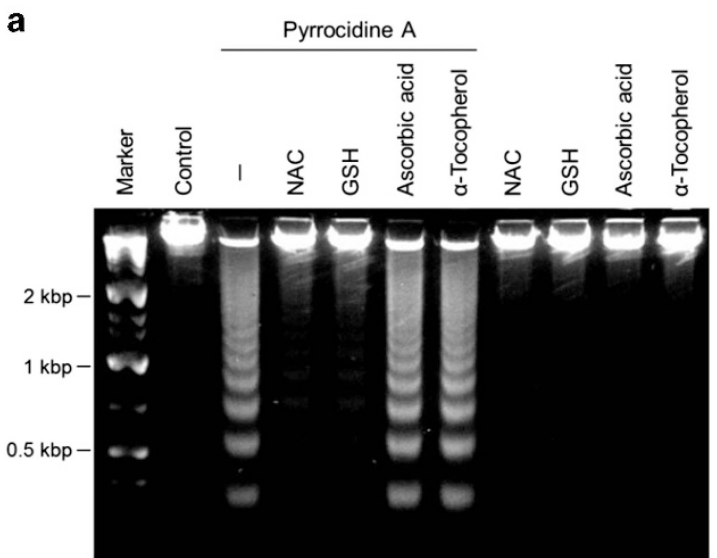

C

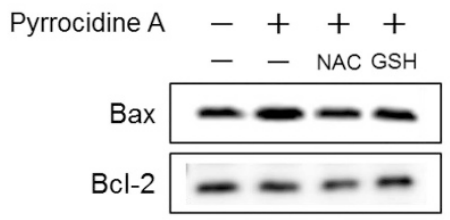

d

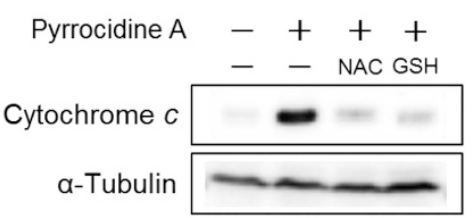

b

Pyrrocidine A -+++

$-\quad$ NAC GSH

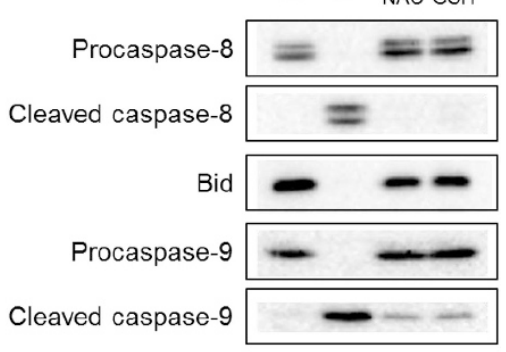

Procaspase-3 - - -

Cleaved caspase-3 $=$

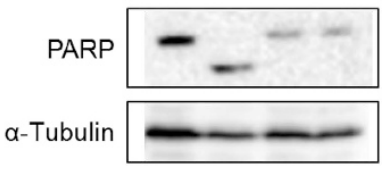

e

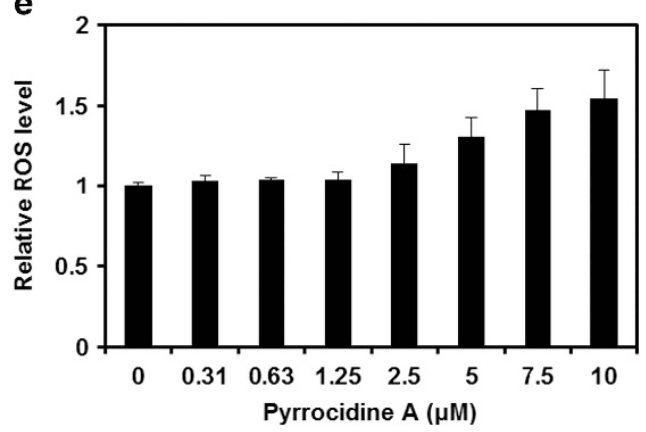

Figure 5 Thiol compounds suppress pyrrocidine A-induced apoptosis. (a) Effect of antioxidants on pyrrocidine A-induced DNA fragmentation. HL60 cells were treated with antioxidants ( $5 \mathrm{~mm}$ NAC, $5 \mathrm{~mm}$ GSH, $5 \mathrm{~mm}$ ascorbic acid or $0.1 \mathrm{~mm} \alpha$-tocopherol) for $1 \mathrm{~h}$, before treatment with $1 \mu \mathrm{m}$ pyrrocidine A for $3 \mathrm{~h}$. DNA was extracted from these cells, and analyzed by agarose gel electrophoresis and stained by ethidium bromide. (b) Effect of antioxidants on the expression of apoptosis-related proteins. HL60 cells were treated with $5 \mathrm{~mm} \mathrm{NAC} \mathrm{or} \mathrm{GSH} \mathrm{for} 1 \mathrm{~h}$, before treatment with $1 \mu \mathrm{m}$ pyrrocidine A for $3 \mathrm{~h}$. These cells were lysed and the prepared cell lysate was subjected to western blotting. (c) Effect of antioxidants on the expression of Bax and Bcl-2. (d) Effect of antioxidants on the release of cytochrome $c$ to cytosolic fraction. HL6O cells were treated with $5 \mathrm{~mm} \mathrm{NAC} \mathrm{or} \mathrm{GSH} \mathrm{for} 1 \mathrm{~h}$, before treatment with $1 \mu \mathrm{m}$ pyrrocidine A for $3 \mathrm{~h}$. These cells were lysed and the prepared whole cell lysate (b, c) and cytosolic fraction (d) were subjected to western blotting. (e) ROS production by pyrrocidine A. HL60 cells were treated with pyrrocidine A for $1 \mathrm{~h}$, and then stained with DCFH-DA. After $30 \mathrm{~min}$, the intensity of the fluorescence was measured. 
A
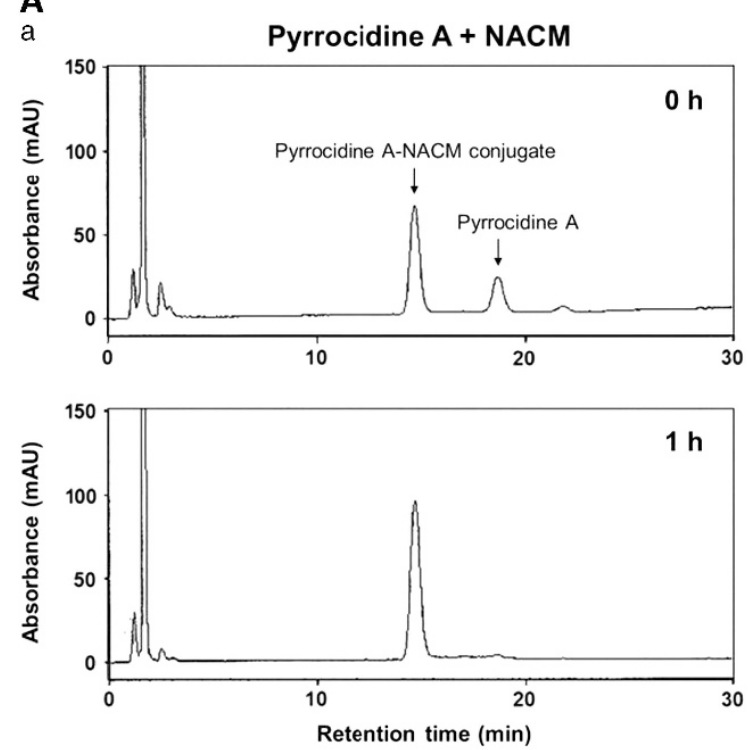

B a Pyrrocidine A
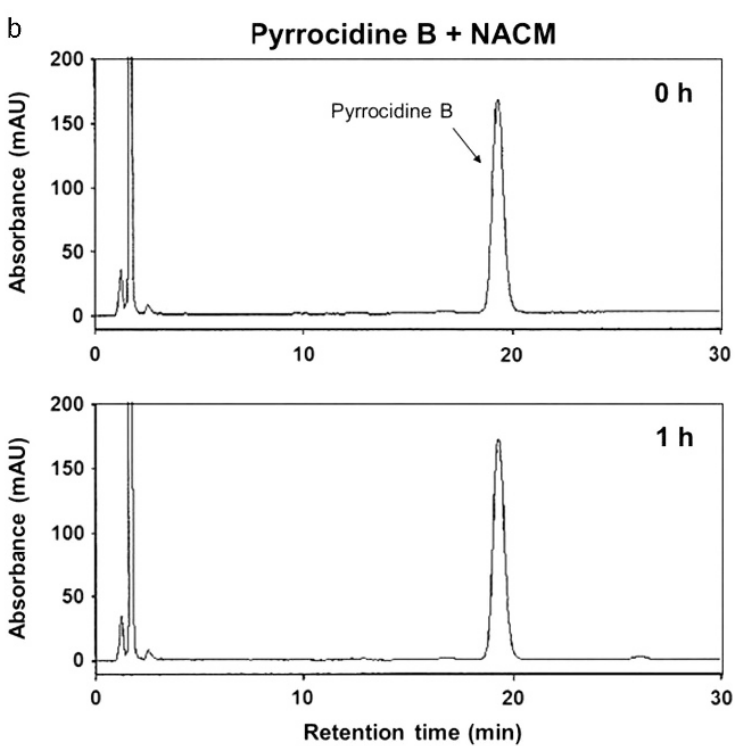

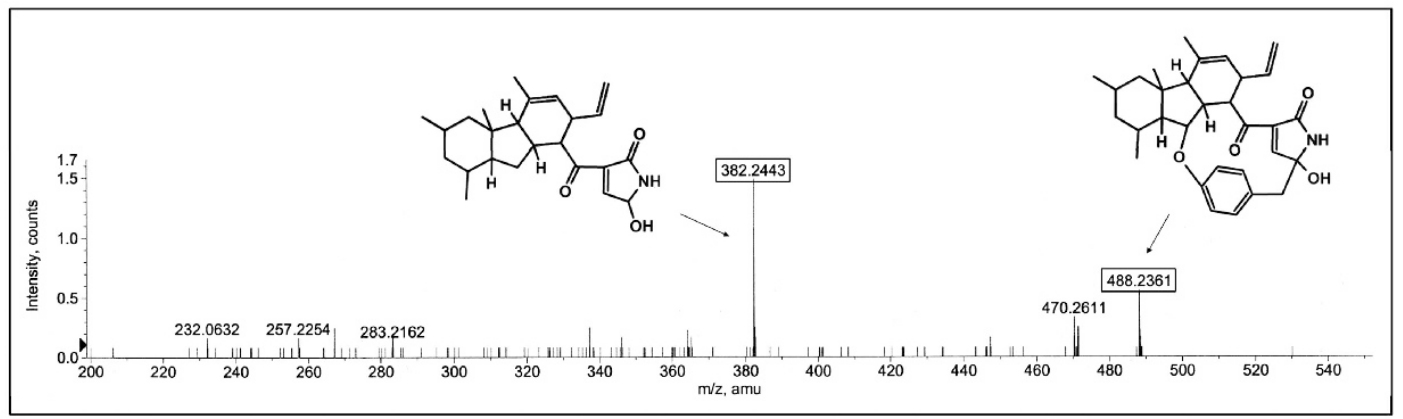

b Pyrrocidine A-NACM conjugate

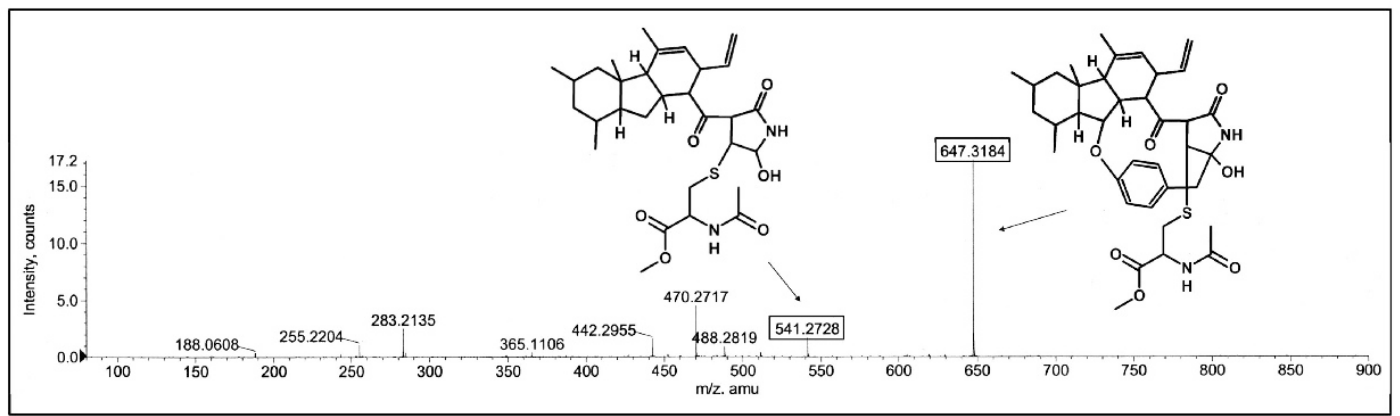

Figure 6 Formation of pyrrocidine A-NACM conjugate. (A) HPLC analysis of the products of pyrrocidine A (a) or pyrrocidine B (b) with NACM. Pyrrocidines A and B (1 mm) were incubated with $10 \mathrm{~mm} \mathrm{NACM}$ in $40 \mu \mathrm{l}$ of $70 \% \mathrm{MeOH}$ solution for $1 \mathrm{~h}$ at $37^{\circ} \mathrm{C}$ and then analyzed by $\mathrm{HPLC}$. (B) LC-ESI-MS/MS analysis of pyrrocidine A (a) and pyrrocidine A-NACM conjugate (b). Proposed chemical structure of pyrrocidine A-NACM conjugates is shown on the chart at the major ion peaks.

potently inhibits the growth of HL60 cells. In spite of the remarkable biological activity, the mode of action of pyrrocidine A remains to be elucidated. In this study, we showed that pyrrocidine $\mathrm{A}$ induced nuclear condensation (Figure 2A) and DNA fragmentation (Figure 2B) through the activation of caspase pathways (Figure $3 \mathrm{~A}$ ), the elevation of $\mathrm{Bax} / \mathrm{Bcl}-2$ ratio (Figure $3 \mathrm{~B}$ ) and release of cytochrome $c$ to the cytosol (Figure 3C) in a dose-dependent manner. Bax is a proapoptotic Bcl-2 family protein and it recruited to mitochondrial outer membrane, and then induces MOMP and the release of mitochondrial proteins such as cytochrome $c$. On the other hand, $\mathrm{Bcl}-2$ is an antiapoptotic protein, and it inhibits induction of MOMP through binding to Bax. Thus, the elevation of $\mathrm{Bax} / \mathrm{Bcl}-2$ ratio is considered as a critically important event in the induction of apoptosis. ${ }^{19}$ Pyrrocidine A-induced release of cytochrome $c$ is probably mediated by the induction of MOMP. In addition, since $\mathrm{z}-\mathrm{VAD}$-fmk suppressed pyrrocidine A-induced DNA fragmentation (Figure 3D), these results 
indicate that pyrrocidine A causes caspase-mediated apoptosis in HL60 cells.

To characterize the mode of action of pyrrocidine A, we utilized JFCR39, a panel of 39 human cancer cell line. The result of this screening indicated that there are no similar compounds (correlation coefficients $r<0.5$ ) in the reference compounds, and the anticancer effect of pyrrocidine $\mathrm{A}$ is therefore different from known clinical drugs. Additionally, pyrrocidine A induced cytotoxicity against various cancer cell lines with a MG-MID value, the mean of the $\log \mathrm{GI}_{50}$ values for the 39 cell lines of -6.64 . This indicates that pyrrocidine A has excellent potential for use as an anticancer agent for the treatment of a variety of cancers.

In previous studies, we found that $\alpha, \beta$-unsaturated carbonyl group is essential to potent cytotoxicity of pyrrocidine A. Pyrrocidine B, an analog lacking the $\alpha, \beta$-unsaturated carbonyl group, induces DNA fragmentation at $20 \mu \mathrm{m}$ in HL60 cells, but is much weaker than that of pyrrocidine A (Figure 2B). ${ }^{21}$ Some of the compounds that contain $\alpha, \beta$ unsaturated carbonyl or $\alpha, \beta$-unsaturated lactone groups, derived from natural resources, ${ }^{2,22}$ for example, curcumin, ${ }^{23}$ zerumbone, ${ }^{24,25}$ piperlongumine $e^{26,27}$ and leptomycin $\mathrm{B},{ }^{28,29}$ exhibit potent and various biological activities including anticancer effects. These compounds can bind covalently with intracellular proteins through their electrophilic moiety, and the interaction is significantly associated with their potent and various biological effects. Therefore, we examined the effects of thiol-containing compounds on the activity of pyrrocidine A. Pyrrocidine A-induced DNA fragmentation was clearly suppressed by NAC and GSH, but other types of antioxidants, ascorbic acid and $\alpha$-tocopherol, did not suppress DNA fragmentation (Figure 5a). The caspase activation, increase of $\mathrm{Bax} / \mathrm{Bcl}-2$ ratio and release of cytochrome $c$ were also inhibited by NAC and GSH (Figures $5 \mathrm{~b}-\mathrm{d}$ ). Furthermore, ROS generation was detected above $2.5 \mu \mathrm{M}$ after $1 \mathrm{~h}$ (Figure 5e), although pyrrocidine A induces DNA fragmentation at $0.5 \mu \mathrm{m}$ after $1 \mathrm{~h}$ (Figure 2B). Therefore, it is suggested that NAC and GSH suppress pyrrocidine A-induced apoptosis via their role not as antioxidants, but as thiol compounds. Indeed, it was confirmed that pyrrocidine A rapidly forms an adduct with NACM at the $\alpha, \beta$-unsaturated carbonyl group by LC-ESI-MS/MS analysis (Figure 6B). ${ }^{20}$ These findings indicated that $\alpha, \beta$-unsaturated carbonyl group of pyrrocidine A has high reactivity with nucleophilic moieties such as thiol groups. It is known that some of the electrophilic compounds generate ROS by binding with the thiol group of GSH, a representative intracellular antioxidant. On the other hand, leptomycin B also covalently binds with NACM or Cys529 of an its target protein CRM1 through its $\alpha, \beta$-unsaturated lactone moiety and this compound potently induces ROS-independent apoptosis in human leukemia cells in spite of modifying the thiol groups. ${ }^{28,29}$ These results suggest that pyrrocidine A as well as leptomycin B do not affect intracellular ROS levels at apoptosis-inducing concentrations because of their low effective dosage. Therefore, the $\alpha, \beta$-unsaturated carbonyl group of pyrrocidine A is essential for its bioactivity, and it is suggested that pyrrocidine A exerts potent antitumor activity through the binding covalently to unidentified target proteins.

Although irreversible inhibitors often result in undesired side effects, some of the irreversible binding drugs have already been used as clinical drugs for diseases including infection, cancer, gastrointestinal and central nervous system with acceptable side-effect profiles. ${ }^{30-32}$ Recently, irreversible inhibitors have been approved as clinical anticancer drugs, for example, Afatinib and Ibrutinib. These two drugs have an $\alpha, \beta$-unsaturated carbonyl group as pharmacophore, and bind covalently with respective targets. Afatinib binds to Cys797 in epidermal growth factor receptor and Cys805 in human epidermal growth factor receptor 2,33 and Ibrutinib binds to Cys481 in Bruton's tyrosine kinase $^{34}$ through the Michael-type addition, and these covalent interactions cause potent and long-lasting inhibitory effects against kinase signaling and the growth of cancer. These clinical cases indicate the potential for the further development of irreversibly binding drugs for cancer therapy.

In conclusion, we have shown that pyrrocidine A induces caspasedependent apoptosis in HL60 cells and its $\alpha, \beta$-unsaturated carbonyl group is highly reactive with nucleophilic thiol moieties. Pyrrocidine A has been known as a promising antimicrobial compound, but there has been no information about its mode of action and molecular target involved in the attractive biological activities. Although further studies are needed about the direct target of pyrrocidine A in cells and/ or in vivo anticancer effects, the results revealed in this study suggest the potential of pyrrocidine $\mathrm{A}$ as a therapeutic agent for the treatment of a wide range of cancers.

\section{CONFLICT OF INTEREST}

The aurthors declare no conflict of interest.

\section{ACKNOWLEDGEMENTS}

We are grateful to Emeritus Professor Don R Phillips of La Trobe University for critical reading of this manuscript. This work was supported by UGAS, Iwate University Student Research Grant Project and Grant-in-Aid for JSPS Fellows.

1 Koehn, F. E. \& Carter, G. T. The evolving role of natural products in drug discovery. Nat Rev. Drug Discov. 4, 206-220 (2005).

2 Drahl, C., Cravatt, B. F. \& Sorensen, E. J. Protein-reactive natural products. Angew. Chem. Int. Ed. 44, 5788-5809 (2005).

3 Selim, K. A., E.-Beih, A. A., A.-Rahman, T. M. \& E.-Diwany, A. I. Biology of endophytic fungi. Curr. Res. Environ. Appl. Mycol. 2, 31-82 (2012).

4 Gunatilaka, A. A. Natural products from plant-associated microorganisms: distribution, structural diversity, bioactivity, and implications of their occurrence. J. Nat. Prod. 69, 509-526 (2006).

5 Debbab, A., Aly, A. H. \& Proksch, P. Bioactive secondary metabolites from endophytes and associated marine derived fungi. Fungal Divers. 49, 1-12 (2011).

6 Chandra, S. Endophytic fungi: novel sources of anticancer lead molecules. Appl. Microbiol. Biotechnol. 95, 47-59 (2012).

7 Shiono, Y. Anthracobic acids A and B, two polyketides, produced by an endophytic fungus Anthracobia sp. Chem. Biodivers. 3, 217-223 (2006).

8 Shiono, Y. \& Murayama, T. New eremophilane-type sesquiterpenoids, eremoxylarins A and B from Xylariaceous endophytic fungus YUA-026. Z. Naturforsch 60b, 885-890 (2005).

9 Ogasawara, Y., Yoshida, J., Shiono, Y., Miyakawa, T. \& Kimura, K. New eremophilane sesquiterpenoid compounds, eremoxylarins $A$ and $B$ directly inhibit calcineurin in a manner independent of immunophilin. J. Antibiot. 61, 496-502 (2008).

10 Shiono, Y. et al. A new benzoxepin metabolite isolated from endophytic fungus Phomopsis sp. J. Antibiot. 62, 533-535 (2009).

11 Shiono, Y. et al. Allantopyrone A, a new alpha-pyrone metabolite with potent cytotoxicity from an endophytic fungus, Allantophomopsis lycopodina KS-97. J. Antibiot. 63 , 251-253 (2010).

12 Yokoigawa, J. et al. Allantopyrone A, an $\alpha$-pyrone metabolite from an endophytic fungus, inhibits the tumor necrosis factor $\alpha$-induced nuclear factor $\kappa B$ signaling pathway. $J$. Antibiot. 68, 71-75 (2015).

13 Shiono, Y. et al. A dimeric pyrrocidine from Neonectria ramulariae is an inhibitor of prolyl oligopeptidase. Phytochem. Lett. 5, 91-95 (2012).

$14 \mathrm{He}, \mathrm{H}$. et al. Pyrrocidines $\mathrm{A}$ and $\mathrm{B}$, new antibiotics produced by a filamentous fungus. Tetrahedron Lett. 43, 1633-1636 (2002).

15 Wicklow, D. T. \& Poling, S. M. Antimicrobial activity of pyrrocidines from Acremonium zeae against endophytes and pathogens of maize. Phytopathology 99 , 109-115 (2009).

16 Tanaka, R. et al. Synthetic study of pyrrocidines: first entry to the decahydrofluorene core of pyrrocidines. Org. Lett. 14, 4886-4889 (2012).

17 Shiono, Y. et al. Pyrrospirones A and B, apoptosis inducers in HL-60 cells, from an endophytic fungus, Neonectria ramulariae Wollenw KS-246. Bioorg. Med. Chem. Lett. 18, 6050-6053 (2008).

18 Kong, D. \& Yamori, T. JFCR39, a panel of 39 human cancer cell lines, and its application in the discovery and development of anticancer drugs. Bioorg. Med. Chem. 20, 1947-1951 (2012).

19 Reed, J. C. Bcl-2 and the regulation of programmed cell death. J. Cell Biol. 124, 1-6 (1994). 
20 Wicklow, D. T., Roth, S., Deyrup, S. T. \& Gloer, J. B. A protective endophyte of maize: Acremonium zeae antibiotics inhibitory to Aspergillus flavus and Fusarium verticillioides. Mycol. Res. 109, 610-618 (2005).

21 Shiono, Y. \& Kimura, K. Endophytic microorganisms as a source of bioactive compounds. BIOACTIVE COMPOUNDS from NATURAL SOURCES, 2nd edn (CRC Press, Taylon \& Francis Group) 551-577 (2011).

22 Gersch, M., Kreuzer, L. \& Sieber, S. A. Electrophilic natural products and their biological targets. Nat. Prod. Rep. 29, 659-682 (2012).

23 Esatbeyoglu, T. et al. Curcumin-From Molecule to Biological Function. Angew. Chem. Int. Ed. Engl. 51, 5308-5332 (2012).

24 Prasannan, R. et al. Key cell signaling pathways modulated by zerumbone: role in the prevention and treatment of cancer. Biochem. Pharmacol. 84, 1268-1276 (2012)

25 Deorukhkar, A. et al. Zerumbone increases oxidative stress in a thiol-dependent ROSindependent manner to increase DNA damage and sensitize colorectal cancer cells to radiation. Cancer Med. 4, 278-292 (2015)

26 Raj, L. et al. Selective killing of cancer cells by a small molecule targeting the stress response to ROS. Nature 475, 231-234 (2011)

27 Halasi, M. et al. ROS inhibitor N-acetyl-L-cysteine antagonizes the activity of proteasome inhibitors. Biochem. J. 454, 201-208 (2013).
28 Kudo, N. et al. Leptomycin B inactivates CRM1/exportin 1 by covalent modification at a cysteine residue in the central conserved region. Proc. Natl Acad. Sci. USA 96, 9112-9117 (1999).

29 Jang, B.-C. et al. Leptomycin B-induced apoptosis is mediated through caspase activation and down-regulation of $\mathrm{Mcl}-1$ and XIAP expression, but not through the generation of ROS in U937 leukemia cells. Biochem. Pharmacol. 68, 263-274 (2004).

30 Singh, J., Petter, R. C., Baillie, T. A. \& Whitty, A. The resurgence of covalent drugs. Nat. Rev. Drug Discov. 10, 307-317 (2011).

31 Smith, A. J., Zhang, X., Leach, A. G. \& Houk, K. N. Beyond picomolar affinities: quantitative aspects of noncovalent and covalent binding of drugs to proteins. J. Med. Chem. 52, 225-233 (2009).

32 Potashman, M. H. \& Duggan, M. E. Covalent modifiers: an orthogonal approach to drug design. J. Med. Chem. 52, 1231-1246 (2009).

33 Solca, F. et al. Target binding properties and cellular activity of afatinib (BIBW 2992), an irreversible ErbB family blocker. J. Pharmacol. Exp. Ther. 343, 342-350 (2012).

34 Pan, Z. et al. Discovery of selective irreversible inhibitors for Bruton's tyrosine kinase. ChemMedChem. 2, 58-61 (2007). 